\title{
Absence of Hepatitis B Resistance Mutants before Introduction of Oral Antiviral Therapy
}

\author{
Martin Moehlen, ${ }^{1}$ Maria De Medina, ${ }^{2}$ Mary Hill, ${ }^{2}$ Lennox Jeffers, ${ }^{2}$ \\ Eugene R. Schiff, ${ }^{2}$ and Paul Martin ${ }^{2}$ \\ ${ }^{1}$ Section of Gastroenterology \& Hepatology, Department of Internal Medicine, School of Medicine, Tulane University, \\ 1430 Tulane Avenue, SL-35, New Orleans, LA 70112, USA \\ ${ }^{2}$ Center for Liver Diseases, University of Miami, School of Medicine, 1500 NW 12th Avenue, Suite 1101, Miami, FL 33136, USA \\ Correspondence should be addressed to Martin Moehlen; martin.moehlen@gmail.com
}

Received 6 July 2013; Accepted 13 August 2013

Academic Editors: C. Domenicotti, Z.-Z. Lin, and D. Morioka

Copyright (C) 2013 Martin Moehlen et al. This is an open access article distributed under the Creative Commons Attribution License, which permits unrestricted use, distribution, and reproduction in any medium, provided the original work is properly cited.

Introduction. The aim of this study was to assess whether hepatitis B virus drug resistant mutations antedated the widespread use of nucleos $(\mathrm{t})$ ide analogues in treatment naive patients. A number of reports have suggested that drug resistant mutants can be detected in apparently treatment naïve patients. Study. Fifty deidentified serum samples collected from 1986 to 1992 from patients with replicative chronic HBV infection at the University of Miami were genotyped and tested for resistance mutations using a line probe assay InnoLiPA HBV DR v2/v3. Serum HBV DNA was measured. All patients had documented chronic HBV infection with a detectable viral load, HBeAg seropositivity, and absence of HIV infection. Results. Of the 50 individuals included, $86 \%$ were male, mean age was $40 \pm 12$ years, and mostly genotype A. The mean HBV DNA was $126 \mathrm{pg} / \mathrm{mL}$ (range 6.4 to 557.0). No mutations were identified. Conclusions. The absence of drug induced mutations in these sera collected several years prior to the introduction of oral antiviral therapy suggests that these mutations do not occur in treatment naïve populations. Detection of drug resistance in an apparently treatment naïve subject suggests either unrecognized prior antiviral therapy or infection by an inoculum from a treatment experienced patient.

\section{Introduction}

Infection with hepatitis B virus (HBV) remains a frequent etiology of cirrhosis and hepatocellular carcinoma with estimated 360 million individuals with chronic infection worldwide [1]. Although vaccination will ultimately reduce the disease burden due to HBV, antiviral therapy can favorably alter its natural history [2]. Goals of therapy include suppression of HBV replication to delay progression of liver disease reducing the risk of hepatic decompensation and hepatocellular carcinoma as well as infectivity to other individuals. Although standard interferon alpha was licensed for the treatment of chronic HBV infection over two decades ago more widespread therapy became feasible with the advent of well-tolerated oral antiviral nucleoside and nucleotide agents. However, shortly after the introduction of the first nucleoside analogue, lamivudine, treatment induced mutations in the viral genome were identified. These mutations resulted in reduced antiviral efficacy and diminished clinical benefit. Subsequently adefovir, a nucleotide analogue, efficacious in presence of lamivudine induced mutations was licensed, but its use was also associated with emergence of genomic antiviral resistance. Antiviral resistance has also been identified with more recently introduced nucleoside analogue, telbivudine, and entecavir but to date no clinically significant mutations have been recognized with tenofovir, a nucleotide analogue.

Society guidelines and treatment algorithms endorse close monitoring of subjects treated with oral antiviral therapies for development of viral mutants [3-5]. A resistance mutation is an amino acid change that decreases sensitivity to an antiviral drug. Mutations can be divided into primary and secondary mutations, the former an amino acid substitution that results in decreased susceptibility to an 
antiviral agent, whereas the latter is compensatory amino acid substitution(s) restoring the functional defect in the HBV polymerase activity associated with primary drug resistance; hence, secondary mutations restore replicative fitness to HBV [5]. The primary resistance mutations are $\mathrm{rtM} 204 \mathrm{~V} / \mathrm{I}$ within the YMDD motif for lamivudine, rtN236T, and/or rtA181T/V for adefovir. Telbivudine has a high degree of cross-resistance with lamivudine, with its primary resistance mutation M204I and secondary mutations L80I/V or L180M [6]. Entecavir has two distinct patterns of resistance that both include the YMDD mutation associated with lamivudine resistance, rtI169T + rtL180M + rtM204V + rtM250V and rtL180M + rtT184G + rtS202I + rtM204V; however, other resistance patterns have been reported [5].

$\mathrm{HBV}$ replication includes an inherently error prone reverse transcriptase, as it does not have a $3^{\prime}-5^{\prime}$ proofreading exonuclease activity. On average approximately $10^{11}$ virions are produced daily [25], with estimated $8 \times 10^{-5}$ mutations/base pair/year [26]. Exposure to oral antiviral agents selects naturally occurring mutations with intrinsic antiviral resistance. Generally these less replicatively fit than "wild type" HBV and therefore do not persist in circulating blood in the absence of an agent inducing resistance. Although drug resistant mutants are selected by antiviral therapy, a number of reports have described their identification in apparently treatment naïve subjects with lamivudine resistance mutations, specifically the M204I/V ranging from 0.8 to $27 \%$ $[7,9,10,13,15,17,18,21,22]$. Implications of $\mathrm{HBV}$ resistance mutants in treatment naïve patients include concerns about the inappropriate use of agents with similar resistance patterns. Furthermore transmission of HBV resistant mutants to others has been recognized. Generally reports of detection of antiviral resistant mutants in treatment naïve patients have been in sera collected after the introduction of the oral antiviral agents; further, several reports do not specify the timeframe from which sera was collected hence making interpretation of this relationship more difficult. The aim of our study was to determine whether resistant mutations were present before the era of antiviral HBV therapy.

\section{Methods and Materials}

We used deidentified residual blood sera collected from July 1986 to July 1992 at the University of Miami. Blood samples were centrifuged, aliquoted, and then stored at $-20^{\circ} \mathrm{C}$ until testing. The study was approved by the University of Miami Institutional Review Board. All of the patients had chronic HBV infection (detectable HBsAg positive for at least 6 months) with a detectable viral load (at least $10 \mathrm{pg} / \mathrm{mL}$ ), HBeAg seropositivity, and absence of HIV coinfection (negative anti-HIV by enzyme immunoassay). All sera were obtained from patients naïve to oral antiviral therapy. Serological markers of HBV were analyzed using commercially available enzyme immunoassay kits (Abbott Laboratories, Abbott Park, IL and Roche). HBV DNA assay was performed with the Abbott Liquid Hybridization HBV DNA quantitative assay (Genostics, Abbott, Chicago, IL). Genotyping was done with the INNO-LiPA HBV genotype
TABLE 1: Clinical and laboratory characteristics of the study population.

\begin{tabular}{lc}
\hline Characteristic & Values \\
\hline Patients $N$ & 50 \\
Male $N(\%)$ & $43(86)$ \\
Female $N(\%)$ & $7(14)$ \\
Years of age, mean \pm SD (range) & $40 \pm 12(19-65)$ \\
HBV DNA, mean pg/mL \pm SD (range) & $126 \pm 121(6-557)$ \\
HBV genotype $N(\%)$ & \\
A & $43(86)$ \\
B & 0 \\
C & $2(3.5)$ \\
D & $2(3.5)$ \\
E & 0 \\
F & $3(6)$ \\
\hline
\end{tabular}

kit (Innogenetics, Belgium). Amplification of HBV DNA was completed with the Roche high pure viral nucleic acid kit (Roche Diagnostics, Indianapolis, IN) and the mutation analysis was accomplished with the INNO-LiPA HBV DR v2/v3 (Innogenetics, Belgium). The INNO-LiPA HBV DR $\mathrm{v} 2 / 3$ reverse hybridization assay can detect single nucleotide mismatches associated with lamivudine, adefovir, and entecavir resistance comprising $5 \%$ or more of the viral population [5]. Descriptive statistics were processed using the SAS 9.2 program package (SAS Institute, Inc., Cary, NC).

\section{Results}

Of the 50 patients whose sera were included $86 \%$ were male, average age was $40 \pm 12$ years, $86 \%$ were genotype A, $6 \%$ were genotype F, 3.5\% were genotype $\mathrm{D}$, and $3.5 \%$ were genotype $\mathrm{C}$ with a mean HBV DNA of $126 \mathrm{pg} / \mathrm{mL}$ (Table 1). No detectable mutations were present in 47 of the 50 samples with INNO-LiPA HBV DR 2/3 testing. Three of the 50 samples had indeterminate results for certain codons (180/181, 236, and 250); these three samples were submitted to InnoGenetics Laboratories in Belgium where direct PCR sequencing confirmed that there were no mutations within these codons.

\section{Discussion}

Our results suggest that prior to the introduction of oral antiviral agents $\mathrm{HBV}$ resistant mutants were absent in treatment naïve patients. Detection of $\mathrm{HBV}$ resistant mutants in treatment naïve patients in other reports has a number of possible explanations. Patients may have contracted HBV by contact with a treatment experienced patient. Alternatively patients may have had unrecognized exposure to antiviral agents, for instance, contained in herbal preparations. A number of other groups have reported the presence of resistant HBV mutants in treatment naïve patients. To determine whether these reports were pertinent the following criteria were applied: (1) treatment naïve hepatitis B treatment, (2) absence of HIV coinfection, (3) hepatitis B DNA polymerase 
TABLE 2: Presence of DNA polymerase mutations in chronic monoinfected hepatitis B treatment naïve.

\begin{tabular}{|c|c|c|c|c|c|c|}
\hline Author, year & Country & Time frame & $N$ & Method(s) & $\begin{array}{c}\text { Presence of DR } \\
\text { mutations }\end{array}$ & $\begin{array}{c}\text { Presence of LAM } \\
\text { DR mutations }\end{array}$ \\
\hline Matsuda et al. 2004 [7] & Japan & 1976-2000 & 50 & PCR & $\mathrm{N}$ & $\mathrm{N}$ \\
\hline Matsuda et al. 2004 [8] & Japan & 1995-2001 & 71 & PCR & $\mathrm{Y}$ & $\mathrm{Y}$ \\
\hline Kobayashi et al. 2001 [9] & Japan & 1997-1999 & 18 & PCR & $\mathrm{Y}$ & $\mathrm{Y}$ \\
\hline $\begin{array}{l}\text { Margeridon-Thermet et al. } \\
2009 \text { [10] }\end{array}$ & United States & 1998-2007 & 17 & PCR/UDPS & $\mathrm{Y}$ & $\mathrm{Y}$ \\
\hline $\begin{array}{l}\text { Amini-Bavil-Olyaee et al. } \\
2008 \text { [11] }\end{array}$ & Iran & 2002-2006 & 147 & PCR & $\mathrm{N}$ & $\mathrm{N}$ \\
\hline Pollicino et al. 2009 [12] & Italy & $2002-2007$ & 100 & PCR & $\mathrm{N}$ & $\mathrm{N}$ \\
\hline Han et al. 2009 [13] & China & $2005-2006$ & 328 & PCR & $\mathrm{Y}$ & $\mathrm{Y}$ \\
\hline Nguyen et al. 2009 [14] & United States & $2005-2008$ & 472 & PCR & $\mathrm{Y}$ & $\mathrm{Y}$ \\
\hline Fung et al. 2008 [15] & Canada & $2006-2008$ & 209 & RHA & $\mathrm{Y}$ & $\mathrm{Y}$ \\
\hline Liu et al. 2010 [16] & China & $2007-2008$ & 192 & PCR & $\mathrm{N}$ & $\mathrm{N}$ \\
\hline Mirandola et al. 2011 [17] & Italy & 2007-2009 & 255 & RHA & $\mathrm{Y}$ & $\mathrm{Y}$ \\
\hline Fung et al. 2009 [18] & Canada & 2007-2009 & 311 & RHA & $\mathrm{Y}$ & $\mathrm{Y}$ \\
\hline Salpini et al. 2011 [19] & Europe & $2007-2010$ & 140 & PCR & $\mathrm{Y}$ & $\mathrm{N}$ \\
\hline Sayan et al. 2010 [20] & Turkey & 2008-2009 & 88 & PCR & $\mathrm{Y}$ & $\mathrm{N}$ \\
\hline Osiowy et al. 2011 [21] & Canada & 2008-2009 & 201 & RHA/UDPS & $\mathrm{Y}$ & $\mathrm{Y}$ \\
\hline $\mathrm{Ng}$ et al. 2009 [22] & Canada & 2008-2009 & 175 & RHA & $\mathrm{Y}$ & $\mathrm{Y}$ \\
\hline Nguyen et al. 2009 [23] & United States & 2009 & 70 & RHA & $\mathrm{N}$ & $\mathrm{N}$ \\
\hline Nguyen et al. 2011 [24] & United States & 2009-2011 & 200 & RHA & $\mathrm{Y}$ & $\mathrm{N}$ \\
\hline
\end{tabular}

Key: time frame: time range of blood sera collection; $N$ : number of naïve treated subjects; method(s): method(s) used to detect genotypic resistance mutations; DR: drug resistance; LAM: lamivudine; PCR: polymerase chain reaction; UDPS: ultradeep pyrosequencing; RHA: reverse hybridization assay; Y: yes; N: no.

mutation testing performed (any method), (4) the time period of blood sera collection specified, and (5) including 10 or more subjects. We identified 18 reports, including abstracts, for further analysis (Table 2). Only one of the eighteen papers examined sera in the before 1995 era, Matsuda et al. [7]. An additional paper performed a phylogenetic cluster analysis on HBV sequences before 1995 from the National Center Biotechnology Institute database [13].

Matsuda et al. evaluated 50 Japanese patients' sera, the majority obtained pre-1995. Twenty (40\%) were asymptomatic carriers, and sera were assessed by PCR (both by enzyme-linked minisequence assay and by restriction fragment length polymorphism). Sera were collected from 1979 to 1989 and the YMDD motif was specifically sought. No mutations were noted. A second group of 10 (20\%) individuals had their sera examined prior to lamivudine therapy and were assessed for surface antigen loss. All screening sera were collected from 1976 to 1992 and sequenced by PCR for YMDD mutation and found to be negative. Lastly, there was a third group of 20 individuals who were treated with lamivudine; however, prior to initiating lamivudine therapy, the YMDD motif was assessed among treatment subjects, and sera had been collected from 1994 to 2000. No treatment induced mutations were detected in this group [7].

In another report Chinese investigators sought to determine if widespread oral antiviral use had increased resistance to therapy and whether drug resistant strains had been transmitted by patients [13]. Direct PCR sequencing was performed from 328 treatment naïve patients, predominantly genotype $\mathrm{C}$ and $\mathrm{HBeAg}$ positive. Approximately $4 \%$ of patients had lamivudine associated viral resistance mutations, less than $1 \%$ had adefovir $(0.6 \%)$, and entecavir $(0.3 \%)$ related viral mutants. Phylogenetics were performed to assess the genetic distance between HBV reverse transcriptase sequences in sera collected between 2005 and 2006 and controls submitted to the National Center for Biotechnology Information (GenBank) before 1995. Phylogenetic analysis is a method used to assess genetic evolutionary changes over a period of time. The cohort compared to the genetic bank was found to be similar (genetic distance of 0.02), allowing the authors to conclude that the advent of nucleos(t)ide therapy did not accelerate evolutionary change [13].

Kobayashi et al. [9] reported the presence of viral mutants in eighteen treatment naïve chronic HBV patients. 13 (72\%) of whom had the YMDD wild type, while 5 (28\%) had mutants. Samples had been collected between 1997 and 1999 from treatment naïve patients. Other reports, with the exception of Matsuda et al. [7], (Table 2) had samples from 1995 onwards, all with variable results and frequencies of viral mutants.

There are some limitations to our study. First, the sample size is relatively small. From our literature search, of the eighteen selected papers (Table 2), 75\% had sample sizes larger than 50, with the average size including approximately 170 patients. Second, we had three of the fifty samples that had indeterminate results on the INNO-LiPA DR2/3 testing. These samples were confirmed to not have resistance 
mutations; however, at the expense of a relatively less sensitive test, direct PCR sequencing. Third, reverse hybridization assay, such as INNO-LiPA is known to be extremely sensitive (able to detect viral resistance constituting 5\% or more of the total viral population); however, the test does not detect novel mutations and may not be as sensitive as ultradeep pyrosequencing (UDPS) [10, 27]. Finally as the samples were deidentified limited demographic information could be obtained about the subjects, such as ethnicity. In regard to ethnicity, however, as the majority of subjects had genotype A, one could infer that they were of North AmericanEuropean descent.

In conclusion, our results support the hypothesis that HBV drug resistance mutations did not antedate introduction of oral antiviral agents and that the detection of drug resistance in an apparently treatment naïve subject suggests either unrecognized prior antiviral therapy or infection by an inoculum from a treatment experienced patient.

\section{Conflict of Interests}

None of the authors has any conflicts of interests.

\section{References}

[1] S. T. Goldstein, F. Zhou, S. C. Hadler, B. P. Bell, E. E. Mast, and H. S. Margolis, "A mathematical model to estimate global hepatitis B disease burden and vaccination impact," International Journal of Epidemiology, vol. 34, no. 6, pp. 1329-1339, 2005.

[2] Y.-F. Liaw and C.-M. Chu, "Hepatitis B virus infection," The Lancet, vol. 373, no. 9663, pp. 582-592, 2009.

[3] E. B. Keeffe, D. T. Dieterich, S.-H. B. Han et al., "A treatment algorithm for the management of chronic hepatitis B virus infection in the United States: 2008 update," Clinical Gastroenterology and Hepatology, vol. 6, no. 12, pp. 1315-1341, 2008.

[4] A. S. F. Lok and B. J. McMahon, "AASLD practice guideline update chronic hepatitis B: update 2009," Hepatology, vol. 50, no. 3, pp. 661-662, 2009.

[5] A. S. Lok, F. Zoulim, S. Locarnini et al., "Antiviral drugresistant HBV: standardization of nomenclature and assays and recommendations for management," Hepatology, vol. 46, no. 1, pp. 254-265, 2007.

[6] Y.-F. Liaw, E. Gane, N. Leung et al., "2-Year GLOBE trial results: telbivudine is superior to lamivudine in patients with chronic hepatitis B," Gastroenterology, vol. 136, no. 2, pp. 486-495, 2009.

[7] M. Matsuda, F. Suzuki, Y. Suzuki et al., "YMDD mutants in patients with chronic hepatitis B before treatment are not selected by lamivudine," Journal of Medical Virology, vol. 74, no. 2, pp. 361-366, 2004.

[8] M. Matsuda, F. Suzuki, Y. Suzuki et al., "Low rate of YMDD motif mutations in polymerase gene of hepatitis $\mathrm{B}$ virus in chronically infected patients not treated with lamivudine," Journal of Gastroenterology, vol. 39, no. 1, pp. 34-40, 2004.

[9] S. Kobayashi, T. Ide, and M. Sata, "Detection of YMDD motif mutations in some lamivudine-untreated asymptomatic hepatitis B virus carriers," Journal of Hepatology, vol. 34, no. 4, pp. 584-586, 2001.

[10] S. Margeridon-Thermet, N. S. Shulman, A. Ahmed et al., "Ultra-deep pyrosequencing of hepatitis b virus quasispecies from nucleoside and nucleotide reverse-transcriptase inhibitor
(NRTI)-treated patients and NRTI-naive patients," Journal of Infectious Diseases, vol. 199, no. 9, pp. 1275-1285, 2009.

[11] S. Amini-Bavil-Olyaee, S. Y. Hosseini, F. Sabahi, and S.M. Alavian, "Hepatitis B virus (HBV) genotype and YMDD motif mutation profile among patients infected with HBV and untreated with lamivudine," International Journal of Infectious Diseases, vol. 12, no. 1, pp. 83-87, 2008.

[12] T. Pollicino, G. Isgrò, R. Di Stefano et al., "Variability of reverse transcriptase and overlapping $S$ gene in hepatitis $B$ virus isolates from untreated and lamivudine-resistant chronic hepatitis B patients," Antiviral Therapy, vol. 14, no. 5, pp. 649-654, 2009.

[13] Y. Han, L. H. Huang, C. M. Liu et al., "Characterization of hepatitis B virus reverse transcriptase sequences in Chinese treatment naive patients," Journal of Gastroenterology and Hepatology, vol. 24, no. 8, pp. 1417-1423, 2009.

[14] M. H. Nguyen, R. T. Garcia, H. N. Trinh et al., "Prevalence of hepatitis B virus DNA polymerase mutations in treatmentnaïve patients with chronic hepatitis B," Alimentary Pharmacology and Therapeutics, vol. 30, no. 11-12, pp. 1150-1158, 2009.

[15] S. K. Fung, T. Mazzulli, M. El-Kashab et al., "Lamivudineresistant mutation among treatment-naive hepatitis $\mathrm{B}$ patients is common and may be associated with treatment failure," Hepatology, vol. 48, supplement 1, p. 703A, 2008.

[16] B.-M. Liu, T. Li, J. Xu et al., "Characterization of potential antiviral resistance mutations in hepatitis $\mathrm{B}$ virus reverse transcriptase sequences in treatment-naïve Chinese patients," Antiviral Research, vol. 85, no. 3, pp. 512-519, 2010.

[17] S. Mirandola, D. Campagnolo, G. Bortoletto, L. Franceschini, M. Marcolongo, and A. Alberti, "Large-scale survey of naturally occurring HBV polymerase mutations associated with anti-HBV drug resistance in untreated patients with chronic hepatitis B," Journal of Viral Hepatitis, vol. 18, no. 7, pp. e212e216, 2011.

[18] S. Fung, F. Wong, T. Mazzulli et al., "Pre-existing antiviralresistant mutation may be associated with primary nonresponse to lamivudine among treatment-naïve chronic hepatitis B patients," Hepatology, vol. 50, supplement 4, p. 523A, 2009.

[19] R. Salpini, V. Svicher, V. Cento et al., "Characterization of drugresistance mutations in HBV D-genotype chronically infected patients, naïve to antiviral drugs," Antiviral Research, vol. 92, no. 2, pp. 382-385, 2011.

[20] M. Sayan, S. Ç. Akhan, and M. Meric, "Naturally occurring amino-acid substitutions to nucleos(t)ide analogues in treatment naive Turkish patients with chronic hepatitis B," Journal of Viral Hepatitis, vol. 17, no. 1, pp. 23-27, 2010.

[21] C. Osiowy, K. A. Ng, J. Ho et al., "Prevalence of nucleoside/nucleotide analogue resistance among treatment-naïve endemically-exposed chronic hepatitis B individuals by ultradeep pyrosequencing," Hepatology, vol. 54, supplement 1, pp. 1067A-1068A, 2011.

[22] K. A. Ng, C. Osiowy, D. K. Wong et al., "Prevalence of lamivudine resistance mutations among treatment-naive endemically exposed chronic hepatitis B individuals is low and not linked to demographic predictors," Hepatology, vol. 50, supplement 4, pp. 508A-509A, 2009.

[23] M. H. Nguyen, H. N. Trinh, R. T. Garcia et al., "No baseline mutations in the hepatitis $\mathrm{B}$ virus reverse transcriptase were detected in patients with treatment-naive chronic hepatitis $\mathrm{B}$ using INNO LIPA HBV DR 3: a prospective study," Hepatology, vol. 50, supplement 4, p. 493A, 2009.

[24] M. H. Nguyen, H. N. Trinh, R. T. Garcia et al., "Hepatitis B virus $(\mathrm{HBV})$ reverse transcriptase mutation is rare in treatment-naive 
patients with chronic hepatitis $\mathrm{B},(\mathrm{CHB})$ : a prospective multicenter study using INNO-LIPA HBV DR 3 assay," Hepatology, vol. 54, supplement 1, p. 1080A, 2011.

[25] M. A. Nowak, S. Bonhoeffer, A. M. Hill, R. Boehme, H. C. Thomas, and H. Mcdade, "Viral dynamics in hepatitis B virus infection," Proceedings of the National Academy of Sciences of the United States of America, vol. 93, no. 9, pp. 4398-4402, 1996.

[26] C. Osiowy, E. Giles, Y. Tanaka, M. Mizokami, and G. Y. Minuk, "Molecular evolution of hepatitis B virus over 25 years," Journal of Virology, vol. 80, no. 21, pp. 10307-10314, 2006.

[27] M. Solmone, D. Vincenti, M. C. F. Prosperi, A. Bruselles, G. Ippolito, and M. R. Capobianchi, "Use of massively parallel ultradeep pyrosequencing to characterize the genetic diversity of hepatitis B virus in drug-resistant and drug-naive patients and to detect minor variants in reverse transcriptase and hepatitis B S antigen," Journal of Virology, vol. 83, no. 4, pp. 1718$1726,2009$. 


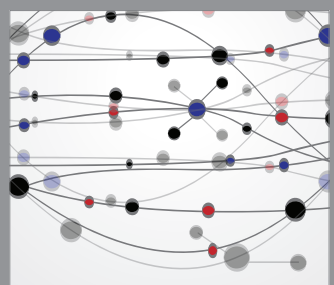

The Scientific World Journal
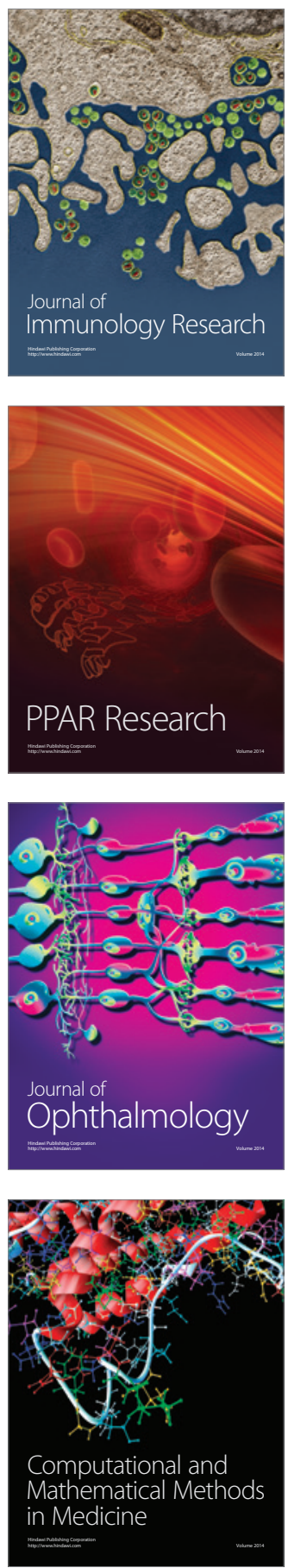

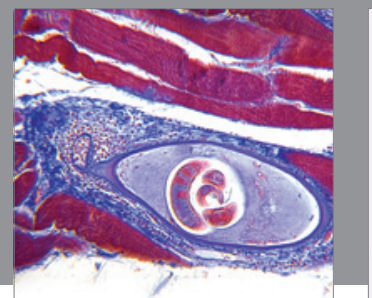

Gastroenterology

Research and Practice
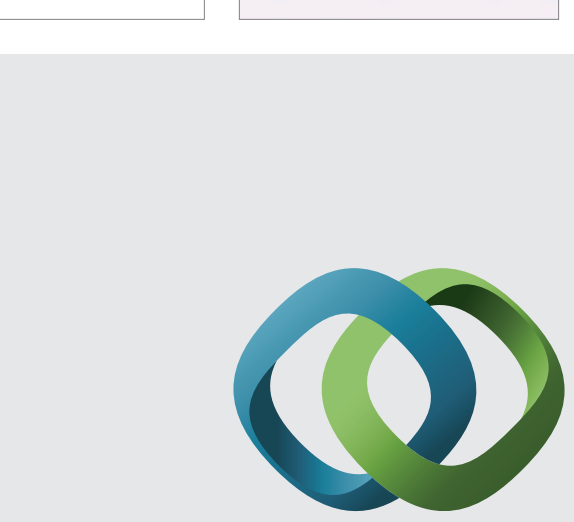

\section{Hindawi}

Submit your manuscripts at

http://www.hindawi.com
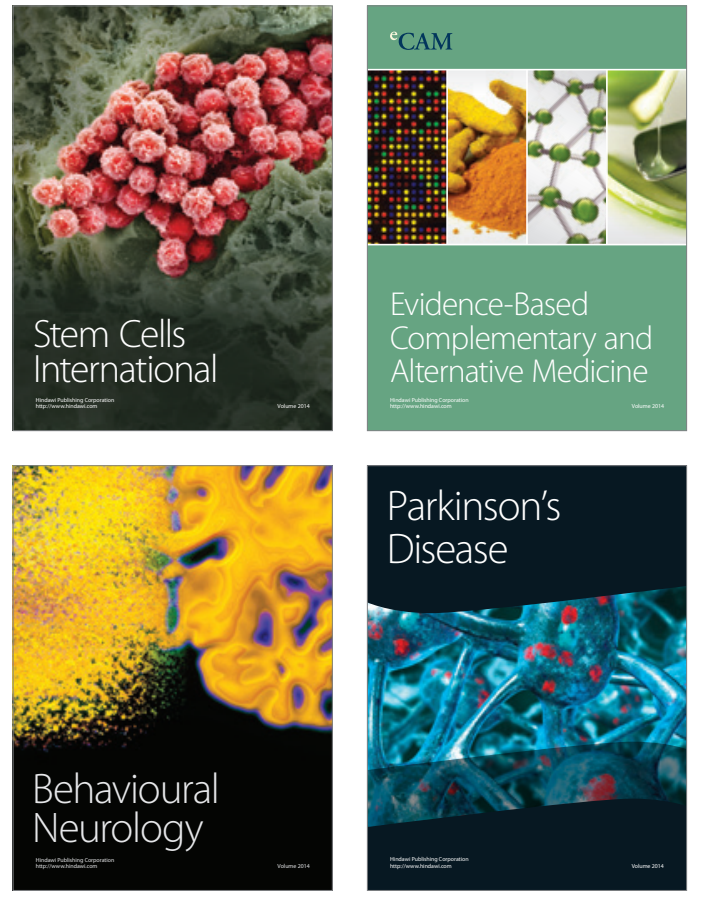
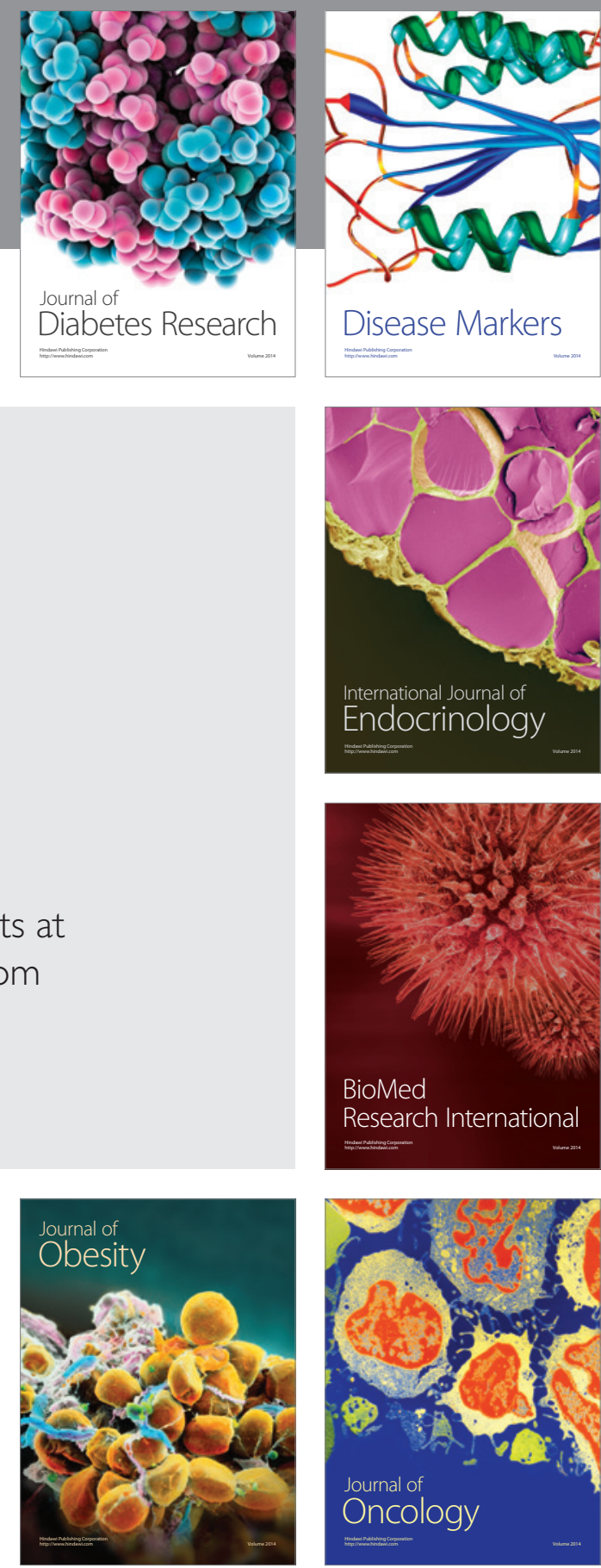

Disease Markers
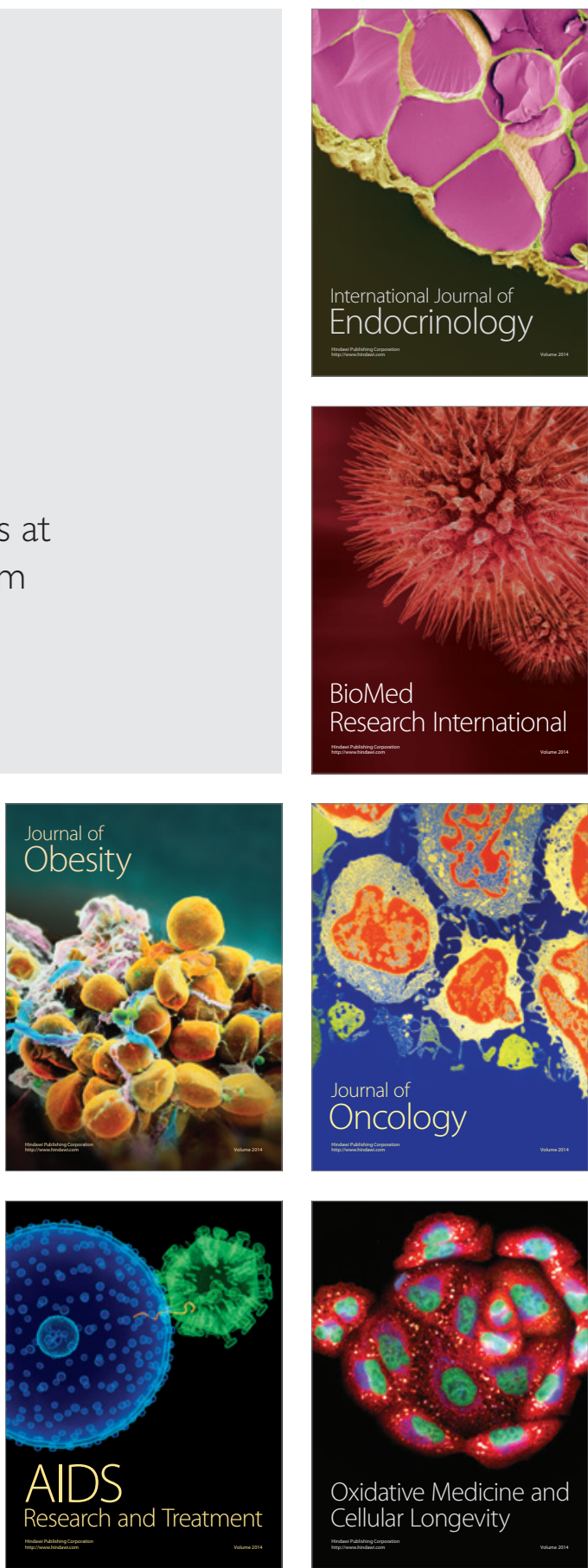